\title{
When Environment Meets Genetics: A Clinical Review of the Epigenetics of Pain, Psychological Factors, and Physical Activity
}

\author{
Andrea Polli, MSc, ${ }^{a, b, c}$ Kelly Ickmans, PhD, ${ }^{a, b, d}$ Lode Godderis, PhD, ${ }^{c, e}$ Jo Nijs, PhD ${ }^{a, b, d}$ \\ From the ${ }^{a}$ Pain in Motion international research group, Brussels, Belgium; ${ }^{b}$ Department of Physiotherapy, Human Physiology and Anatomy, \\ Rehabilitation Sciences and Physiotherapy, Vrije Universiteit Brussel, Brussels; 'Department of Public Health and Primary Care, Centre for \\ Environment and Health, KU Leuven, Leuven; ${ }^{d}$ Department of Physical Medicine and Physiotherapy, University Hospital Brussels, Brussels; and \\ ${ }^{e}$ External Service for Prevention and Protection at Work, IDEWE, Heverlee, Belgium.
}

\begin{abstract}
Epigenetic mechanisms represent a link between the environment and gene function. Recent research shows how early life stress, inflammation, and physical activity can influence gene expression through epigenetic mechanisms. Epigenetic changes-such as DNA methylation and microRNA interference-can be measured in humans and might soon become important biological markers. Epigenetic marks can accompany clinical assessment to measure the effectiveness of various interventions, such as exercise therapy. In addition, epigenetics is improving the understanding of important underlying mechanisms related to the central nervous system, the opioidergic system, and stress responses. Epigenetics is closing a gap in our explanatory abilities and should be implemented to broaden the field of rehabilitation sciences, promote a mechanism-based clinical reasoning, and develop new treatments. In the present review, we focused on epigenetic mechanisms related to pain, psychological factors (such as fear and anxiety), and physical activity, translating relevant findings from these 3 different, yet related, areas of cardinal importance for clinicians.
\end{abstract}

Archives of Physical Medicine and Rehabilitation 2018; $\mathbf{\square} \mathbf{\square} \mathbf{\square} \mathbf{\square} \mathbf{\square}$

(C) 2018 by the American Congress of Rehabilitation Medicine

Epigenetics refers to those mechanisms that determine a change in gene expression but do not alter the underlying DNA sequence (table 1). ${ }^{1}$ Epigenetic mechanisms might therefore interfere with protein expression and function without modifying the actual code of the gene.

One example highlighting the importance of epigenetic processes can be found during embryonic development. Every cell in an organism contains the same genetic code; however, different groups of cells have distinct phenotypes that fulfill very different functions. Cell phenotypes are determined during embryonic development by highly regulated epigenetic mechanisms that selectively silence some genes while allowing others to express themselves. $^{2,3}$

Andrea Polli is a research fellow funded by the Flanders Research Foundation. Kelly Ickmans is a post-doctoral research fellow funded by the Flanders Research Foundation. Jo Nijs holds a chair funded by the Berekuyl Academy, The Netherlands.

Disclosures: none.
Epigenetics has gained increasing attention, as many epigenetic mechanisms are inheritable and modifiable and link gene expression to environmental changes. ${ }^{4}$ This adds an additional layer of understanding to our current knowledge. The accumulating evidence indicates that genetics cannot consistently predict gene expression, and we now know that most chronic conditions result from complex gene-environment interactions. ${ }^{5,6}$ Environmental factors, such as exposure to toxic chemical elements (eg, solvents, tobacco, drugs), diet, physical activity or inactivity, and stressful events, are associated with altered DNA methylation-a widely studied epigenetic mechanism. ${ }^{7-10}$ For instance, a single session of aerobic exercise can dramatically change gene expression in over 350 genes. $^{11}$

Epigenetics has already led to breakthrough findings that contribute to our understanding of the pathogenesis of Alzheimer disease, ${ }^{12}$ psychiatric illness, ${ }^{13}$ and cancer. ${ }^{14}$ Cancer growth and differentiation involve alterations in the expression of several genes. DNA in tumor cells is globally hypomethylated, thus promoting chromosomal instability and overexpression of genes 
implicated in tumor growth. ${ }^{15}$ Likewise, genes encoding for tumor suppressors are hypermethylated, and their expression is therefore reduced. ${ }^{15}$ This picture represents a hallmark of most forms of cancer and is the basis for developing future therapeutic interventions.

Clinical sciences have yet to take up the challenge and explore this new, exciting area. In the present review, we discuss how epigenetics can be relevant to broadening the field of clinical and rehabilitation sciences. More specifically, we focus on the epigenetics of pain, psychological factors, and physical activity, translating the relevance of early findings for clinicians.

The field of rehabilitation can potentially gain considerable benefit from combining clinical assessments with epigenetic marker measurements. Epigenetics can be used to assess and target underlying mechanisms - allowing us to tailor, as much as possible, our treatments to each patient-and to measure the biological effects of our treatments, and it might play a crucial role in predicting treatment responses.

\section{Epigenetic mechanisms}

The best characterized epigenetic processes can be classified in 3 main categories: histone modifications and chromatin remodeling, DNA methylation, and noncoding RNA (ncRNA) interference. Further information on these epigenetic processes can be found in the review carried out by Jaenisch and Bird. ${ }^{16}$

Histone modifications refer to biochemical changes that occur in histone proteins (see table 1). ${ }^{17}$ Histones are a group of 8 proteins around which DNA is wrapped, forming the beads-on-astring structure of chromatin. Modifications of histones (eg, acetylation, phosphorylation, and methylation of histone proteins) can induce changes in chromatin arrangement, increasing or decreasing structural density. ${ }^{18}$ Figure 1 schematically illustrates the most common mechanisms of histone modification and how they affect chromatin rearrangement and transcription. When chromatin is highly condensed, proteins, enzymes, and transcription factors cannot easily access DNA; hence, transcription is hampered. Conversely, when chromatin is less compressed, access to DNA is facilitated, and so is transcription.

DNA methylation is arguably the most widely studied epigenetic modification. ${ }^{19}$ A group of enzymes - the so-called DNA methyltransferases - works to add methyl groups to DNA. Methyl groups bound to DNA interfere with the binding of transcription factors, which in turn silences gene expression (fig 2). More recently, hydroxymethylation has also been described. ${ }^{20}$ Hydroxymethylation reverses DNA methylation and is therefore a crucial mechanism for reprogramming gene function. ${ }^{21}$

\begin{tabular}{|ll|}
\hline List of abbreviations: \\
BDNF & brain-derived neurotrophic factor \\
CNS & central nervous system \\
HDAC & histone deacetylase \\
HPA & hypothalamic-pituitary-adrenal \\
miRNA & microRNA \\
ncRNA & noncoding RNA \\
NR3C1 & nuclear receptor subfamily 3 group C member 1 \\
OPRM1 & $\mu$-opioid receptor-1 \\
TRPV1 & transient receptor potential vanilloid 1 \\
TRPA1 & transient receptor potential ankyrin 1 \\
\hline
\end{tabular}

Another mechanism that is known to induce gene silencing is ncRNA interference. ${ }^{22,23}$ The term $n c R N A$ refers to circulating RNA molecules that do not serve to encode functional proteins. On the contrary, they might interfere with transcription, binding to and degrading those RNA molecules that would normally translate into proteins. The ncRNA family comprises several types of RNA, namely microRNA (miRNA), small interfering RNA, and long noncoding RNA.

These 3 mechanisms are highly interconnected. For example, DNA methylation might impede transcription of ncRNA that would have silenced a certain gene. ${ }^{24}$ In this case, DNA methylation would result in an increase-rather than decrease-in the expression of that gene. Similar statements can be made about the interconnections between miRNA and chromatin modification, as miRNA can directly target histone deacetylases (HDACs), a group of enzymes that remove acetyl groups from histone proteins, thus influencing chromatin arrangement. ${ }^{25}$

Epigenetic processes are essential for the development and functioning of normal cells. Therefore, it is important that some epigenetic mechanisms remain stable throughout life. For instance, helper $\mathrm{T}$ cells have a central role in orchestrating immune responses. Once they acquire their specific immunologic identity, they become able to release a variety of cytokines. Histone methylation and subsequent changes in chromatin structure allow $\mathrm{T}$ cells to maintain their acquired status. ${ }^{26}$

On the contrary, some other hugely important functions require a combination of stable and transient, activity-dependent epigenetic processes. ${ }^{27}$ Synaptic plasticity and the ability to form new neural connections are key features of our central nervous system (CNS). Transcription factors, such as cAMP response elementbinding proteins 1 and $2^{28}$ and brain-derived neurotrophic factor (BDNF), ${ }^{29}$ appear to be of major importance. In particular, BDNF is related to activity-dependent long-term synaptic potentiation, a cellular phenomenon highly related to associative learning and memory formation. ${ }^{30,31}$ Epigenetic processes are required for such functions. DNA methylation is triggered in the hippocampus during learning, and the blocking of DNA methyltransferases or small ncRNA interferes with memory formation. ${ }^{32,33}$

\section{Epigenetics and pain}

Several genes have been associated with different pain syndromes and altered pain thresholds. ${ }^{34}$ The catechol-O-methyltransferase gene (a gene-regulated catecholamine degrader) ${ }^{35-37}$; the $\mu$-opioid receptor-1 (OPRM1) gene ${ }^{38,39}$; genes regulating TRPV1 and TRPA1 receptors ${ }^{40,41}$; and $\mathrm{BDNF}^{42}$ appear to play a relevant role. However, gene polymorphisms do not always explain gene expression. ${ }^{42}$ Environmental factors are considered at least equally important in the development of chronic pain. ${ }^{43}$

A number of epigenetic processes in several CNS regions are related to inflammatory or neuropathic pain in animals. DNA methylation in the prefrontal cortex and amygdala is negatively correlated with the magnitude of nociceptive sensitization after nerve injury. ${ }^{44}$ Several miRNAs are up- or downregulated in the spinal cord and brain and are associated with hyperalgesia and allodynia. $^{45}$

Initial interesting results from clinical studies have also been published. In painful neuropathies, miRNA expression differs when compared with healthy controls. ${ }^{46}$ In an animal model of visceral hypersensitivity, upregulation of one particular form of miRNA (miR-199) was associated with inhibition of TRPV1 
Table 1 Glossary

\begin{tabular}{|c|c|}
\hline Useful Terms & Description \\
\hline Gene & A specific sequence of DNA that stores information needed for synthesis of RNA or proteins. \\
\hline DNA sequence & $\begin{array}{l}\text { A sequence of } 4 \text { different molecules, or nucleotides-namely adenine }(A) \text {, guanine }(G) \text {, cytosine }(C) \text {, and thymine } \\
(T) \text { - that serve as a script to encode functional products. A single change in the DNA sequence is called an SNP. } \\
\text { SNPs can be benign, but in some cases can also have dramatic consequences, such as increased susceptibility to } \\
\text { certain diseases. }\end{array}$ \\
\hline Gene expression & The process by which information from a given gene is used to express functional products, such as RNA or proteins. \\
\hline Histones & $\begin{array}{l}\text { Proteins that pack and order DNA within a cell's nucleus. DNA is wrapped around multiple complexes of } 8 \text { histones each. } \\
\text { Thanks to this organization, DNA length is } 40,000 \text { times shorter. }\end{array}$ \\
\hline Transcription & $\begin{array}{l}\text { The process by which a given sequence of DNA is copied in an RNA sequence. If the initial DNA sequence is a gene, } \\
\text { transcription represents the first step of gene expression. Otherwise, the same process can produce miRNA. }\end{array}$ \\
\hline Translation & $\begin{array}{l}\text { The second step of gene expression. The information carried by the RNA sequence is read, allowing the production of a } \\
\text { specific amino acid chain. This sequence of amino acids then folds and gives rise to a functional protein. }\end{array}$ \\
\hline
\end{tabular}

Abbreviations: RNA, ribonucleic acid; SNP, single nucleotide polymorphism.

signaling and decreased hyperalgesia. ${ }^{47}$ The TRPV1 receptor is expressed in sensory fibers; transduces noxious heat, protons, and other chemical compounds like capsaicin; and has been extensively associated with nociceptor sensitization. ${ }^{41}$ In addition, miR199 has a sequence complementary to TRPV1, and higher levels of circulating miR-199 inhibit TRPV1 expression. ${ }^{47}$ In line with this evidence, decreased expression of miR-199 miRNA is associated with pain in patients with irritable bowel syndrome. ${ }^{47}$

Higher methylation of the OPRM1 gene is associated with decreased expression of $\mu$-opioid receptors and predicts pain after spinal fusion. ${ }^{48}$ OPRM1 methylation seems crucial for opioid release regulation in acute pain and might explain why some subjects show reduced responses to endogenous and exogenous opioids. $^{48}$

Patients with fibromyalgia show several differently methylated regions in genes controlling DNA repair, synaptic signaling, and neuronal excitability (eg, BDNF). ${ }^{49,50}$ In a large longitudinal study, Livshits et $\mathrm{al}^{51}$ used genome-wide methylation analysis to assess epigenetic modifications in an independent dataset of 1608 twins as well as 50 identical twin pairs (ie, with identical DNA sequences) who were discordant for chronic widespread pain. They found associations in several genes, most notably those related to immune functions and regulation of tumor necrosis factor, interleukin-17, and protein kinase C. Differences in methylation could only explain $6 \%$ of the variance; however, genome-wide methylation was performed on stable methylation sites that were therefore less prone to environmental influences.

Similarly, Bell et al $^{52}$ studied 25 identical twins who differed in their sensitivity to noxious heat stimuli. They analyzed the entire epigenome of subjects, searching for differentially methylated regions. The strongest association was found in the TRPAl gene. The TRPA1 receptor is well known for its role in peripheral nerve sensitization secondary to inflammation. ${ }^{53}$

Epigenetics offers the exciting possibility of studying relevant underlying mechanisms of chronic pain, thus allowing us to close a gap in our explanatory abilities. One such mechanism is the excitability of the nervous system, as it determines how nociceptive and non-nociceptive stimuli are modulated. Central sensitization-a form of maladaptive neuroplasticity that determines an increase in neuronal excitability - is a key underlying mechanism in many chronic pain conditions, such as osteoarthritis, fibromyalgia, chronic whiplash, postcancer pain, neuropathic pain, and chronic low back pain. ${ }^{54-57}$ Initial research shows its predicting and mediating role in different chronic conditions. ${ }^{58}$ Epigenetic mechanisms are understudied in relation to central sensitization. One animal study showed that miR-7a reverses neuropathic pain by regulating neuronal excitability. ${ }^{59}$ Histone deacetylation also contributes to nociceptive hypersensitivity, which is reversed by HDAC inhibitors. ${ }^{60}$

Finally, associations have been found between migraine and methylation of calcitonin gene-related peptide. ${ }^{61}$ Calcitonin generelated peptide is a well-characterized peptide known for its role in neuronal sensitization. ${ }^{62}$ Despite the fact that research on the role of epigenetics in pain is in its infancy, emerging evidence suggests that the study of epigenetics might help unravel key elements in the field, such as vulnerability to pain.

\section{Epigenetics of psychological factors}

Psychological factors are important in the pain experience. ${ }^{63}$ Fear of pain negatively influences physical activity ${ }^{64}$ as well as return to work ${ }^{65}$ and can play a role in the maintenance of pain symptoms. ${ }^{66}$ Anxiety and stress predict chronic pain in the long term and might mediate vulnerability to pain. ${ }^{67-69}$ Learning mechanisms are able to facilitate and maintain a state of CNS hyperexcitability, ${ }^{70}$ which is a predictive and mediating factor in chronic pain. ${ }^{71-73}$ Intriguingly, early life adversity and psychological stress during development determine higher levels of fear and anxiety in adults ${ }^{74-76}$ and increase the risk of developing chronic pain. ${ }^{77}$ Unraveling these mechanisms can be of crucial importance for people who are experiencing pain.

Epigenetic mechanisms might provide the biological mechanism whereby, in some subjects, fear appears to be easier to learn, or why stress responses are enhanced in some more than others. Fear consolidation shares various mechanisms with learning and memory formation. Fear can, in fact, be learned through associative learning. Using a contextual fear-conditioning paradigm, where a novel context (in this case, a different room) was paired with an electrical foot shock, a single 6-minute session of fear conditioning was able to induce a rapid increase in BDNF methylation in the hippocampus. ${ }^{29}$ This rapid increase was associated with histone acetylation and altered gene transcription during fear consolidation. ${ }^{29}$ 


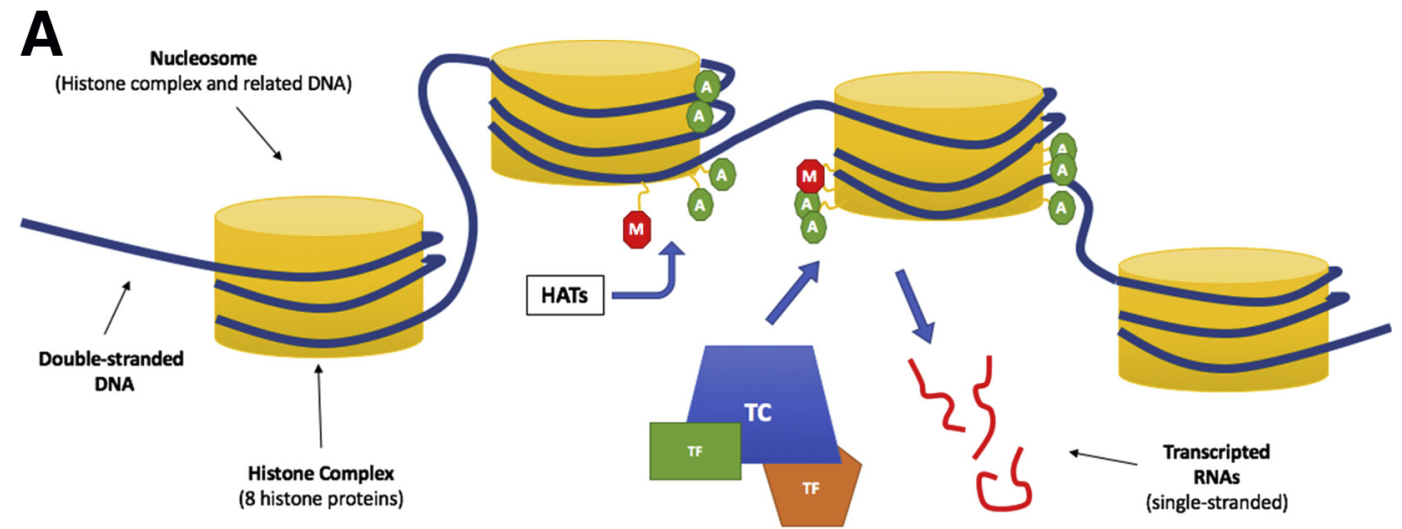

B

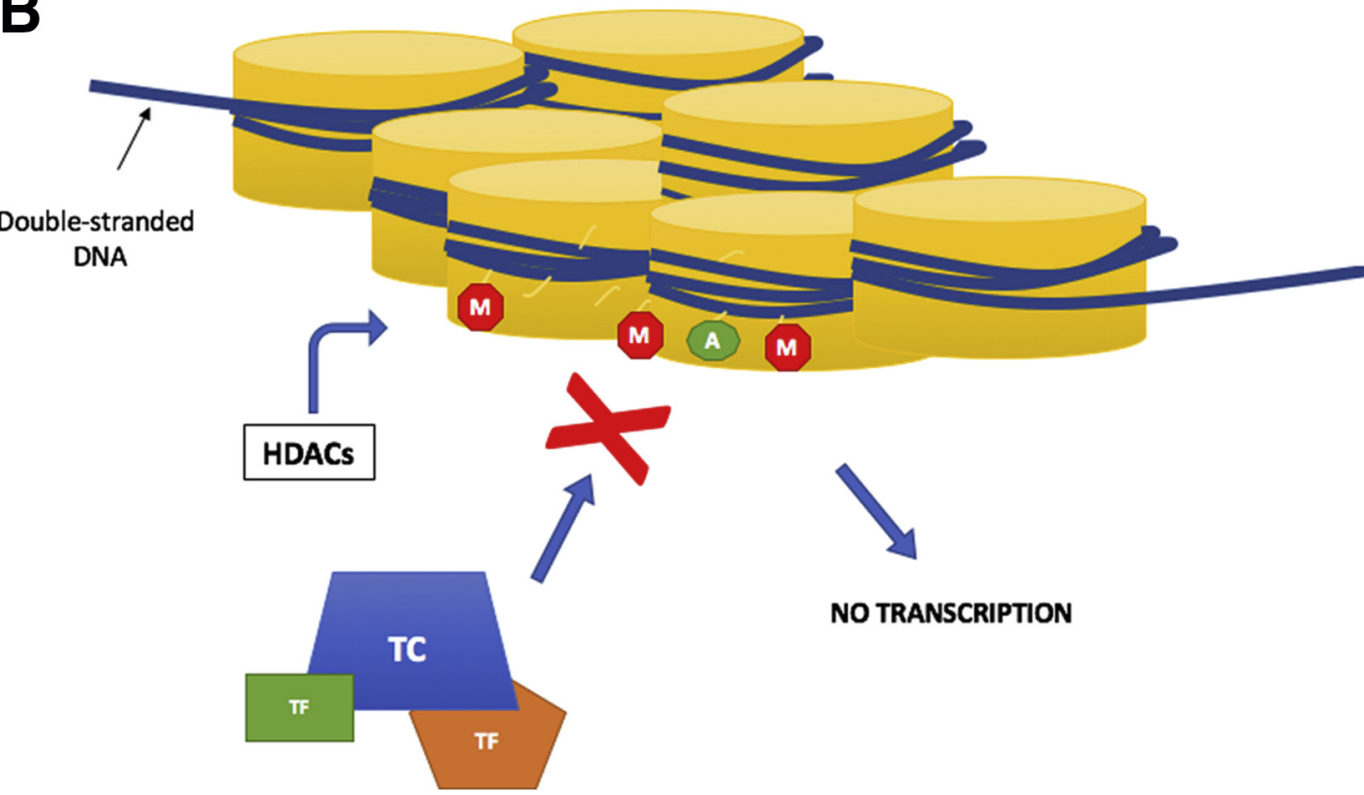

Fig 1 Histone modification and its effects on DNA transcription. DNA is wrapped twice around each histone complex. How tightly it is wrapped depends on enzymes such as histone acetyl-transferases (HATs), histone deacetylases (HDACs), histone methyltransferases (HMT), etc, which in turn change conformation. A, HATs transfer acetyl groups to histones. DNA is repelled by acetylased histones and loosens up. Transcription complexes (TC) and transcription factors (TF) can easily access DNA, and transcription can occur. This loosened arrangement is called euchromatin and is commonly referred to as a beads-on-a-string structure. The final product is a single strand of RNA that will be used as a template and translated into a functional protein. B, HDACs remove acetyl groups from histones, attracting the DNA to the histones. This causes DNA to become tightly wrapped around histones and confers on chromatin a packed arrangement (ie, heterochromatin). Transcription factors cannot easily access DNA, and transcription is hampered. HMTs add a methyl group (ME) to histones. However, their effects are more complex. Generally, HATs foster heterochromatin and inhibit transcription too, but in some cases, depending on where the binding site is, they can actually promote transcription. Methylation of histones should not be confused with DNA methylation.

Stress is also able to facilitate neuronal excitability and foster central sensitization. This can occur via glial recruitment and activation $^{78}$ or via hyperactivation of the hypothalamic-pituitary-adrenal (HPA) axis and glucocorticoid release. ${ }^{74-76,79}$ A systematic review of the relation between stress and epigenetic modifications identified significant differences in the gene methylation of mainly 3 genes: $N R 3 C 1, B D N F$, and the serotonin transporter gene solute carrier family 6 member $4 .{ }^{80} \mathrm{NR} 3 \mathrm{Cl}$ might be of particular importance for stress responses, as it is the gene that encodes glucocorticoid synthesis in the hippocampus. Early life stress decreases $\mathrm{NR} 3 \mathrm{Cl}$ expression and increases sensitivity to stress in adult animals. ${ }^{75,81}$ However, $N R 3 C 1$ is upregulated in rats receiving high maternal care during early development, which then mediates enhanced glucocorticoid feedback and promotes stress-resilient phenotypes. $^{75,81} \mathrm{NR} 3 \mathrm{Cl}$ promoter methylation, HPA axis responsiveness, and glucocorticoid levels in offspring have been correlated with maternal anxiety during the last months of pregnancy. ${ }^{82}$ Taken together, these data would suggest that exposure to psychological stress might induce epigenetic changes, such as DNA methylation of the NR3Cl gene, that are in turn capable of influencing stress responses in later life.

Thus, vulnerability to stress might be the result of repetitive epigenetic modifications that in turn influence HPA axis response and glucocorticoid release during stressful events. Glucocorticoids have large effects on brain neuroplasticity and synaptic transmission. ${ }^{83}$ In addition, when their release is prolonged, glialmediated neuroinflammation is enhanced. ${ }^{10,78}$ This, as already mentioned, facilitates central sensitization and, possibly, pain. 


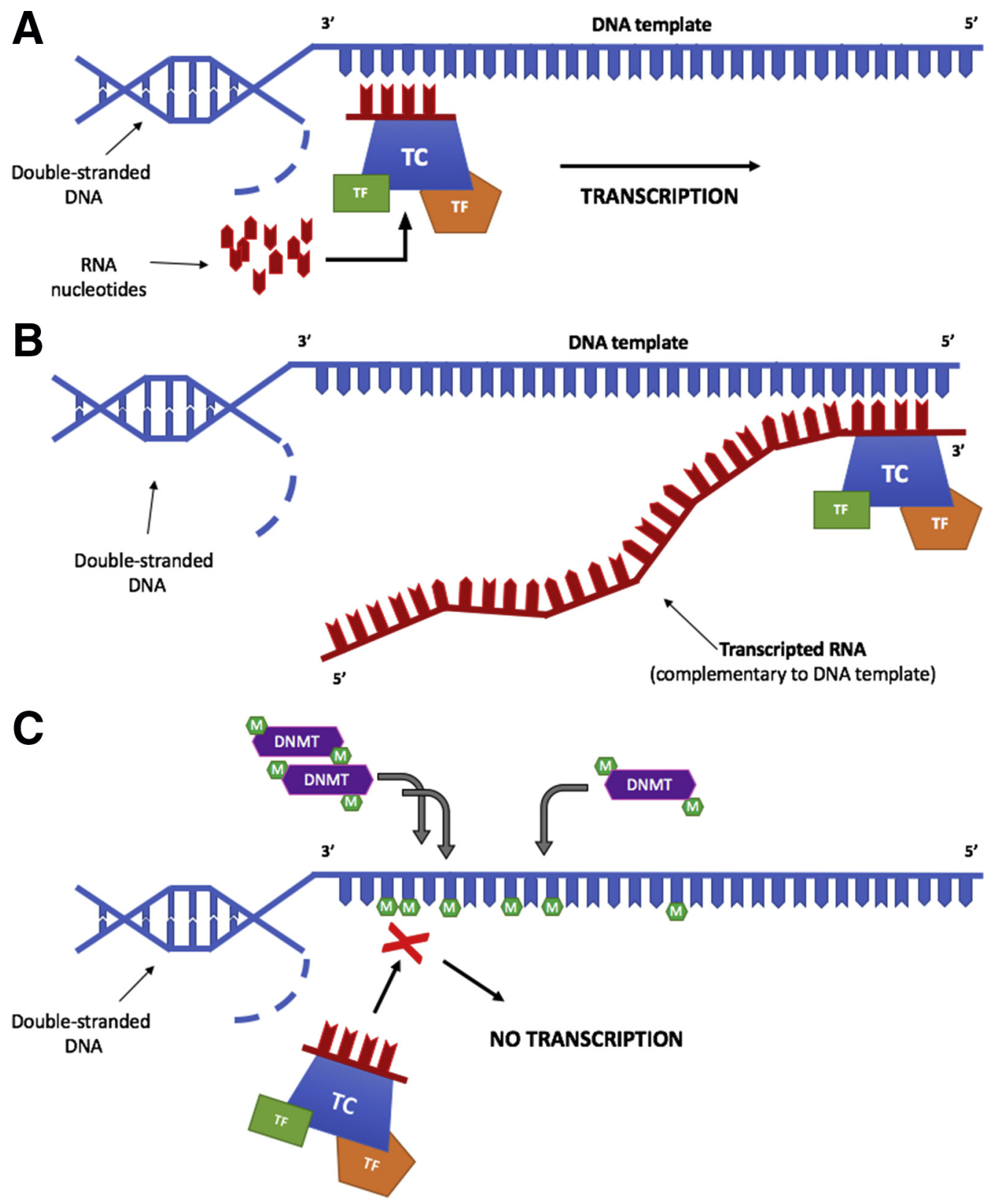

Fig 2 DNA methylation influences transcription. A, Transcription involves a series of mechanisms that allows transcription factors (TF) and transcription complexes (TC) to bind together, open DNA, and then bind the DNA template of interest. B, From there, RNA nucleotides are added to the DNA template to form an RNA sequence that will be complementary to the DNA template. C, However, if DNA is methylated because of the action of DNA methyltransferases (DNMTs), TC/TF binding sites will no longer be complementary to the DNA, and transcription will stop.

New drugs have in fact been developed to specifically target epigenetic mechanisms. These drugs mainly target histone methylation, histone acetylation, and miRNA to regulate inflammation, immune function, and HPA axis response. ${ }^{84-86}$

\section{Epigenetics and exercise}

Exercise induces changes in DNA methylation in over 350 skeletal muscle genes. ${ }^{11,87}$ Most of them, but not all, have been found to be demethylated after exercise. ${ }^{88}$ Interestingly, these changes are larger in older people ${ }^{87}$ and dependent on exercise intensity. ${ }^{89}$ More intense exercise is associated with less methylation.
Recent research has demonstrated for the first time that muscles have an epigenetic memory that influences muscle growth. ${ }^{90}$ A few weeks of strength training increases muscle mass and reduces methylation levels in several genes. Some of these genes stay hypomethylated for weeks after the end of training even if muscle size has returned to baseline. ${ }^{90}$ Interestingly, if muscles undergo a second period of training ( 8 weeks after the end of the first), many genes show even more rapid demethylation afterward. ${ }^{90}$ This seems to suggest that a short strengthening program epigenetically primes muscles and facilitates better responses to subsequent training programs.

A number of exercise-induced CNS changes have been described as well. ${ }^{91}$ Several brain regions show exercise-induced epigenetic 
changes. ${ }^{91}$ One single session of treadmill exercise reduces histone deacetylation in rats ${ }^{92}$ in a manner similar to the effect of HDAC inhibitors. As mentioned, HDACs have been associated with increased neuronal excitability. ${ }^{60}$ These findings might help explain the well-known hypoalgesic effect of exercise. ${ }^{93}$

HDAC inhibition fosters BDNF expression as well. ${ }^{94}$ BDNF seems to represent an essential link between exercise and brain functions. ${ }^{95}$ It increases after physical activity, mediates synaptic plasticity, and promotes cognitive functions. ${ }^{96}$ However, BDNF has also been associated with maladaptive plasticity and central sensitization in people with chronic pain. ${ }^{97}$ Levels of BDNF are in fact higher in the serum and plasma of patients with fibromyalgia. ${ }^{98}$ A further increase following exercise might thus explain the worsening of symptoms seen in some patients with chronic pain. ${ }^{99}$ The aforementioned double action attributable to BDNF is puzzling, and, to our knowledge, no study has tried to elucidate its underlying mechanisms. Epigenetics offers an intriguing possibility for targeting this issue, as the $B D N F$ gene has a complex structure and several ways in which it can encode proteins. ${ }^{100}$ It is possible that different epigenetic mechanisms encode for BDNF expression in different regions (eg, CNS or peripheral nerves) or with different functions.

As demonstrated in healthy people, regular physical activity induces changes in circulating cytokines as well. ${ }^{10}$ Physical activity is associated with increased methylation of tumor necrosis factor (a proinflammatory cytokine) and decreased methylation of interleukin-10 (an anti-inflammatory cytokine). This suggests that physical activity plays a positive role in regulating inflammation.

Finally, epigenetic changes after a single bout of exercise have also been observed in some genes. For instance, peroxisome proliferator-activated receptor gamma coactivator 1-alpha shows rapid demethylation after exercise. ${ }^{89}$ Interestingly, the same gene is hypermethylated in patients with diabetes. This might suggest a novel mechanism by which exercise is beneficial for diabetic patients. ${ }^{89}$

In summary, epigenetics is improving our understanding of the physiology of exercise and of the susceptibility to certain diseases. ${ }^{101}$ Current evidence indicates that both a single bout of exercise and regular physical activity induce changes in the genes that regulate nociceptive processes, fear learning, and stress responses as well as those that are involved in the pathophysiology of neuropathies and chronic diseases. Physical activity acts in a manner similar to an array of drugs that targets multiple mechanisms at different levels, all at once.

\section{Future directions and challenges}

In the present review, we have described the relevance epigenetics will have for the clinical sciences in the near future. Epigenetics might provide biological markers that can be used to assess and target, with our treatments, the underlying mechanisms, allowing us to tailor, as much as possible, our treatments to each patient. In addition, epigenetics can be used to measure the biological effects of treatments that are already widely used, such as physical activity and exercise. Combining clinical assessments with epigenetic marker measurements will greatly increase our understanding of those interventions and will hopefully confer more importance on nonpharmacologic treatments.

Epigenetic markers might soon provide new drug targets and mechanisms. New drugs, such as HDAC inhibitors, are currently being tested in cancer and neurologic disorders in preclinical and phase I clinical trials, with initial promising results. ${ }^{102}$ Similarly, innovative genome editing technologies, such as clustered regularly interspaced short palindromic repeats-associated protein- 9 nuclease, ${ }^{103}$ will soon allow scientists to synthetize miRNA capable of selectively altering gene function. Clinicians might soon be able to take advantage of new medications and technologies to foster the implementation of their interventions. For example, some people with chronic fatigue syndrome, fibromyalgia, and inflammatory diseases show a worsening in symptoms following a single bout of exercise. ${ }^{99,104,105}$ This logically contributes to lower adherence to physical activity programs by these patients. ${ }^{106,107}$ In an attempt at improving adherence to physical activity, research has focused on nonpharmacologic approaches, with initial encouraging results; patient education, cognitive behavioral therapies, and graded activity seem to increase exercise adherence. ${ }^{108,109}$ However, the clinical effectiveness of these approaches is not always satisfactory. ${ }^{110,111}$ More research exploring nonpharmacologic treatment is clearly needed and welcome.

We would also like to suggest that new, exciting possibilities might develop combining behavioral therapies with epigeneticbased pharmacologic treatments. For instance, one of the mechanisms that can at least partially explain exercise-induced hyperalgesia in patients with chronic widespread pain is the overreaction of the immune system to exercise. ${ }^{104,105}$ New drugs and technologies might be able to manipulate gene expression and reduce immune responses to exercise in these patients, facilitating their engagement in physical activity, thus taking advantage of all the beneficial effects induced by physical activity.

Scientific knowledge about epigenetics is far from comprehensive, and many issues remain to be investigated. Most research on the topic has been conducted on animals and has yet to be translated to the clinical setting. More translational research on humans is needed to deepen our knowledge, explore the real clinical potential, and eventually make technology more accessible to labs and clinics. In addition, future research should transfer accumulating evidence from other fields, such as the aforementioned clinical trials investigating HDAC inhibitors in people with cancer and neurologic disorders, ${ }^{102}$ to the fields of pain and rehabilitation.

Finally, future research should consider some unanswered issues. One such issue is the fact that epigenetic regulation is sitespecific. ${ }^{112}$ Epigenetic changes in one aspect of the body (eg, the spinal cord) might not be reflected in another (eg, blood). As human studies, to reduce invasiveness, assess mainly epigenetic modifications in blood or saliva, ${ }^{20,113}$ research should focus on identifying those changes that can be reliably assessed in accessible sites.

Another issue that future research needs to consider when designing new clinical trials is temporal stability of epigenetic markers. It has been shown that the degree of DNA methylation stability is gene-dependent and varies from high to very low stability. ${ }^{114}$ This is important, as high within-gene variability can potentially reduce the power of a study and should be considered when calculating the sample size of new research. Research on epigenetics is increasing exponentially, and we foresee that many questions will soon be answered.

\section{Conclusions}

To conclude, we feel the need to remark that epigenetic processes-even though they might potentially be very relevant for diagnosis, follow-up, and treatment purposes - will always remain 
secondary measures. Patient satisfaction, values, and self-reported improvements will always be the primary and most important endpoint and should not be replaced by any biological measure. However, initial promising research has shown that early biomarker measurements are able to inform clinical practice-for instance, by predicting susceptibility to the development of secondary complications, such as epilepsy after a traumatic brain injury. ${ }^{115}$ Given the potential that epigenetics might hold in the near future, we would urge researchers and clinicians working in the field of rehabilitation to be attentive to the development of this rapidly increasing and exciting field and consider combining clinical measures with more biological ones.

\section{Keywords}

Epigenomics; Exercise; Methylation; Pain; Rehabilitation

\section{Corresponding author}

Andrea Polli, MSc, Rehabilitation Sciences and Physiotherapy, Vrije Universiteit Brussel, Laarbeeklaan 103, 1090 Jette, Brussels, Belgium.E-mail address: andrea.polli@vub.be.

\section{References}

1. Henikoff S. Epigenetics. Epigenetics 2009;2:13.

2. Zardo G, Cimino G, Nervi C. Epigenetic plasticity of chromatin in embryonic and hematopoietic stem/progenitor cells: therapeutic potential of cell reprogramming. Leukemia 2008;22:1503-18.

3. Blomen VA, Boonstra J. Stable transmission of reversible modifications: maintenance of epigenetic information through the cell cycle. Cell Mol Life Sci 2011;68:27-44.

4. Holliday R. Epigenetics: a historical overview. Epigenetics 2006;1: 76-80.

5. Egger G, Liang G, Aparicio A, Jones PA. Epigenetics in human disease and prospects for epigenetic therapy. Nature 2004;429:457-63.

6. Denk F, McMahon SB. Chronic pain: emerging evidence for the involvement of epigenetics. Neuron 2012;73:435-44.

7. Godderis L, De Raedt K, Tabish AM, et al. Epigenetic changes in lymphocytes of solvent-exposed individuals. Epigenomics 2012;4: 269-77.

8. Pauwels S, Duca RC, Devlieger R, et al. Maternal methyl-group donor intake and global DNA (Hydroxy)methylation before and during pregnancy. Nutrients 2016;8.

9. De Nys S, Duca RC, Nawrot T, et al. Temporal variability of global DNA methylation and hydroxymethylation in buccal cells of healthy adults: association with air pollution. Environ Int 2018;111:301-8.

10. Horsburgh S, Robson-Ansley P, Adams R, Smith C. Exercise and inflammation-related epigenetic modifications: focus on DNA methylation. Exerc Immunol Rev 2015;21:26-41.

11. Denham J, Marques FZ, O’Brien BJ, Charchar FJ. Exercise: putting action into our epigenome. Sports Med 2014;44:189-209.

12. Wang B, Zhong Y, Zhao Z, Miao Y. Epigenetic suppression of hippocampal BDNF mediates the memory deficiency induced by amyloid fibrils. Pharmacol Biochem Behav 2014;126:83-9.

13. Ikegame T, Bundo M, Murata Y, Kasai K, Kato T, Iwamoto K. DNA methylation of the BDNF gene and its relevance to psychiatric disorders. J Hum Genet 2013;58:434-8.

14. Li BE, Ernst P. Two decades of leukemia oncoprotein epistasis: the MLL1 paradigm for epigenetic deregulation in leukemia. Exp Hematol 2014;42:995-1012.
15. Kulis M, Esteller M. DNA methylation and cancer. Adv Genet 2010; 70:27-56.

16. Jaenisch R, Bird A. Epigenetic regulation of gene expression: how the genome integrates intrinsic and environmental signals. Nat Genet 2003;33(Suppl):245-54.

17. Campos EI, Reinberg D. Histones: annotating chromatin. Annu Rev Genet 2009;43:559-99.

18. Bannister AJ, Kouzarides T. Regulation of chromatin by histone modifications. Cell Res 2011;21:381-95.

19. Robertson KD. DNA methylation and human disease. Nat Rev Genet 2005;6:597-610.

20. Godderis L, Schouteden C, Tabish A, et al. Global methylation and hydroxymethylation in DNA from blood and saliva in healthy volunteers. Biomed Res Int 2015;2015:845041.

21. Richa R, Sinha RP. Hydroxymethylation of DNA: an epigenetic marker. EXCLI J 2014;13:592-610.

22. Yao B, Christian KM, He C, Jin P, Ming G, Song H. Epigenetic mechanisms in neurogenesis. Nat Rev Neurosci 2016;17:537-49.

23. Chuang JC, Jones PA. Epigenetics and microRNAs. Pediatr Res 2007;61(Pt 2):24-9.

24. Han L, Witmer PD, Casey E, Valle D, Sukumar S. DNA methylation regulates microRNA expression. Cancer Biol Ther 2007;6:1284-8.

25. Bianchi M, Renzini A, Adamo S, Moresi V. Coordinated actions of microRNAs with other epigenetic factors regulate skeletal muscle development and adaptation. Int J Mol Sci 2017;18.

26. Nakayama T, Yamashita M. Initiation and maintenance of Th2 cell identity. Curr Opin Immunol 2008;20:265-71.

27. Crepaldi L, Riccio A. Chromatin learns to behave. Epigenetics 2009; 4:23-6.

28. Rajasethupathy P, Antonov I, Sheridan R, et al. A role for neuronal piRNAs in the epigenetic control of memory-related synaptic plasticity. Cell 2012;149:693-707.

29. Lubin FD, Roth TL, Sweatt JD. Epigenetic regulation of BDNF gene transcription in the consolidation of fear memory. J Neurosci 2008; 28:10576-86.

30. Abbott LF, Nelson SB. Synaptic plasticity: taming the beast. Nat Neurosci 2000;3(Suppl):1178-83.

31. Leal G, Afonso PM, Salazar IL, Duarte CB. Regulation of hippocampal synaptic plasticity by BDNF. Brain Res 2015;1621:82-101.

32. Cortés-Mendoza J, Díaz de León-Guerrero S, Pedraza-Alva G, PérezMartínez L. Shaping synaptic plasticity: the role of activity-mediated epigenetic regulation on gene transcription. Int J Dev Neurosci 2013; 31:359-69.

33. Lubin FD. Epigenetic gene regulation in the adult mammalian brain: multiple roles in memory formation. Neurobiol Learn Mem 2011;96:68-78.

34. Foulkes T, Wood JN. Pain genes. PLoS Genet 2008;4.

35. Oertel B, Lötsch J. Genetic mutations that prevent pain: implications for future pain medication. Pharmacogenomics 2008;9:179-94.

36. Tammimäki A, Männistö PT. Catechol-O-methyltransferase gene polymorphism and chronic human pain: a systematic review and meta-analysis. Pharmacogenet Genomics 2012;22:673-91.

37. Zubieta J-K, Heitzeg MM, Smith YR, et al. COMT val158met genotype affects mu-opioid neurotransmitter responses to a pain stressor. Science 2003;299:1240-3.

38. Bjorland S, Moen A, Schistad E, Gjerstad J, Røe C. Genes associated with persistent lumbar radicular pain; a systematic review. BMC Musculoskelet Disord 2016;17:500.

39. Tour J, Lofgren M, Mannerkorpi K, et al. Gene-to-gene interactions regulate endogenous pain modulation in fibromyalgia patients and healthy controls-antagonistic effects between opioid and serotoninrelated genes. Pain 2017;158:1194-203.

40. Nilius B, Appendino G, Owsianik G. The transient receptor potential channel TRPA1: from gene to pathophysiology. Pflugers Arch 2012; 464:425-58.

41. Ugarte GD, Diaz E, Biscaia M, Stehberg J, Montecino M, van Zundert B. Transcription of the pain-related TRPV1 gene requires RUNX1 and C/EBP $\beta$ factors. J Cell Physiol 2013;228:860-70. 
42. Generaal E, Milaneschi Y, Jansen R, Elzinga BM, Dekker J, Penninx BW. The brain-derived neurotrophic factor pathway, life stress, and chronic multi-site musculoskeletal pain. Mol Pain 2016;12.

43. Buchheit T, Van de Ven T, Shaw A. Epigenetics and the transition from acute to chronic pain. Pain Med 2012;13:1474-90.

44. Tajerian M, Alvarado S, Millecamps M, et al. Peripheral nerve injury is associated with chronic, reversible changes in global DNA methylation in the mouse prefrontal cortex. PLoS One 2013;8:e55259.

45. Descalzi G, Ikegami D, Ushijima T, Nestler EJ, Zachariou V, Narita M. Epigenetic mechanisms of chronic pain. Trends Neurosci 2015;38:237-46

46. Leinders M, Uceyler N, Thomann A, Sommer C. Aberrant microRNA expression in patients with painful peripheral neuropathies. J Neurol Sci 2017;380:242-9.

47. Zhou Q, Yang L, Larson S, et al. Decreased miR-199 augments visceral pain in patients with IBS through translational upregulation of TRPV1. Gut 2016;65:797-805.

48. Chidambaran V, Zhang X, Martin LJ, et al. DNA methylation at the mu-1 opioid receptor gene (OPRM1) promoter predicts preoperative, acute, and chronic postsurgical pain after spine fusion. Pharmgenomics Pers Med 2017;10:157-68.

49. de Andrade DC, Maschietto M, Galhardoni R, et al. Epigenetics insights into chronic pain: DNA hypomethylation in fibromyalgia-a controlled pilot-study. Pain 2017;158:1473-80.

50. Menzies V, Lyon DE, Archer KJ, et al. Epigenetic alterations and an increased frequency of micronuclei in women with fibromyalgia. Nurs Res Pract 2013;2013:795784.

51. Livshits G, Malkin I, Freidin MB, et al. Genome-wide methylation analysis of a large population sample shows neurological pathways involvement in chronic widespread musculoskeletal pain. Pain 2017; 158:1053-62.

52. Bell JT, Loomis AK, Butcher LM, et al. Differential methylation of the TRPA1 promoter in pain sensitivity. Nat Commun 2014;5:2978.

53. McNamara CR, Mandel-Brehm J, Bautista DM, et al. TRPA1 mediates formalin-induced pain. Proc Natl Acad Sci 2007;104:13525-30.

54. Woolf CJ. Central sensitization: implications for the diagnosis and treatment of pain. Pain 2011;152(Suppl 3):2-15.

55. Van Oosterwijck J, Nijs J, Meeus M, Paul L. Evidence for central sensitization in chronic whiplash: a systematic literature review. Eur J Pain 2013;17:299-312.

56. Nijs J, Meeus M, van Oosterwijck J, et al. In the mind or in the brain? Scientific evidence for central sensitisation in chronic fatigue syndrome. Eur J Clin Invest 2012;42:203-12.

57. Lluch E, Torres R, Nijs J, Van Oosterwijck J. Evidence for central sensitization in patients with osteoarthritis pain: a systematic literature review. Eur J Pain 2014;18:1367-75.

58. Nijs J, Apeldoorn A, Hallegraeff H, et al. Low back pain: guidelines for the clinical classification of predominant neuropathic, nociceptive, or central sensitization pain. Pain Physician 2015;18:E333-46.

59. Sakai A, Saitow F, Miyake N, Miyake K, Shimada T, Suzuki H. MiR$7 \mathrm{a}$ alleviates the maintenance of neuropathic pain through regulation of neuronal excitability. Brain 2013;136:2738-50.

60. Matsushita Y, Araki K, Omotuyi OI, Mukae T, Ueda H. HDAC inhibitors restore $\mathrm{C}$-fibre sensitivity in experimental neuropathic pain model. Br J Pharmacol 2013;170:991-8.

61. Wan D, Hou L, Zhang X, et al. DNA methylation of RAMP1 gene in migraine: an exploratory analysis. J Headache Pain 2015;16:90.

62. Iyengar S, Ossipov MH, Johnson KW. The role of calcitonin generelated peptide in peripheral and central pain mechanisms including migraine. Pain 2017;158:543-59.

63. Fritz JM, George SZ. Identifying psychosocial variables in patients with acute work-related low back pain: the importance of fearavoidance beliefs. Phys Ther 2002;82:973-83.

64. Trost Z, France CR, Thomas JS. Pain-related fear and avoidance of physical exertion following delayed-onset muscle soreness. Pain 2011;152:1540-7.

65. De Jong JR, Vlaeyen JW, Van Eijsden M, Loo C, Onghena P. Reduction of pain-related fear and increased function and participation in work-related upper extremity pain (WRUEP): effects of exposure in vivo. Pain 2012;153:2109-18.

66. Bliokas VV, Cartmill TK, Nagy BJ. Does systematic graded exposure in vivo enhance outcomes in multidisciplinary chronic pain management groups? Clin J Pain 2007;23:361-74.

67. Aparicio VA, Ortega FB, Carbonell-Baeza A, Cuevas-Toro AM, Delgado-Fernández M, Ruiz J. Anxiety, depression and fibromyalgia pain and severity. Behav Psychol 2013;21:381-92.

68. Chapman CR, Tuckett RP, Song CW. Pain and stress in a systems perspective: reciprocal neural, endocrine, and immune interactions. J Pain 2008;9:122-45.

69. Rosenbloom BN, Katz J, Chin KY, et al. Predicting pain outcomes after traumatic musculoskeletal injury. Pain 2016;157:1733-43.

70. Nijs J, Lluch Girbes E, Lundberg M, Malfliet A, Sterling M. Exercise therapy for chronic musculoskeletal pain: innovation by altering pain memories. Man Ther 2015;20:216-20.

71. Nijs J, Van Houdenhove B, Oostendorp RA. Recognition of central sensitization in patients with musculoskeletal pain: application of pain neurophysiology in manual therapy practice. Man Ther 2010;15:135-41.

72. Baert IA, Lluch E, Mulder T, Nijs J, Noten S, Meeus M. Does presurgical central modulation of pain influence outcome after total knee replacement? A systematic review. Osteoarthritis Cartilage 2016;24:213-23

73. Lluch Girbes E, Duenas L, Barbero M, et al. Expanded distribution of pain as a sign of central sensitization in individuals with symptomatic knee osteoarthritis. Phys Ther 2016;96:1196-207.

74. Levine S. Developmental determinants of sensitivity and resistance to stress. Psychoneuroendocrinology 2005;30:939-46.

75. Meaney MJ, Szyf M, Seckl JR. Epigenetic mechanisms of perinatal programming of hypothalamic-pituitary-adrenal function and health. Trends Mol Med 2007;13:269-77.

76. Hoffmann A, Spengler D. DNA memories of early social life. Neuroscience 2014;264:64-75.

77. Burke NN, Finn DP, McGuire BE, Roche M. Psychological stress in early life as a predisposing factor for the development of chronic pain: clinical and preclinical evidence and neurobiological mechanisms. J Neurosci Res 2017;95:1257-70.

78. Nijs J, Loggia ML, Polli A, et al. Sleep disturbances and severe stress as glial activators: key targets for treating central sensitization in chronic pain patients? Expert Opin Ther Targets 2017;21:817-26.

79. Russell GM, Henley DE, Leendertz J, et al. Rapid glucocorticoid receptor-mediated inhibition of hypothalamic-pituitary-adrenal ultradian activity in healthy males. J Neurosci 2010;30:6106-15.

80. Bakusic J, Schaufeli W, Claes S, Godderis L. Stress, burnout and depression: a systematic review on DNA methylation mechanisms. J Psychosom Res 2017;92:34-44.

81. Mueller BR, Bale TL. Sex-specific programming of offspring emotionality after stress early in pregnancy. J Neurosci 2008;28:9055-65.

82. Zannas AS, West AE. Epigenetics and the regulation of stress vulnerability and resilience. Neuroscience 2014;264:157-70.

83. Schouten M, Aschrafi A, Bielefeld P, Doxakis E, Fitzsimons CP. MicroRNAs and the regulation of neuronal plasticity under stress conditions. Neuroscience 2013;241:188-205.

84. Oppermann U. Why is epigenetics important in understanding the pathogenesis of inflammatory musculoskeletal diseases? Arthritis Res Ther 2013;15:209.

85. Baxter D, McInnes IB, Kurowska-Stolarska M. Novel regulatory mechanisms in inflammatory arthritis: a role for microRNA. Immunol Cell Biol 2012;90:288-92.

86. Chen WP, Bao JP, Hu PF, Feng J, Wu LD. Alleviation of osteoarthritis by trichostatin A, a histone deacetylase inhibitor, in experimental osteoarthritis. Mol Biol Rep 2010;37:3967-72.

87. Brown WM. Exercise-associated DNA methylation change in skeletal muscle and the importance of imprinted genes: a bioinformatics meta-analysis. Br J Sports Med 2015;49:1568-78.

88. Nitert MD, Dayeh T, Volkov $\mathrm{P}$, et al. Impact of an exercise intervention on DNA methylation in skeletal muscle from first-degree relatives of patients with type 2 diabetes. Diabetes 2012;61:3322-32. 
89. Barrès R, Yan J, Egan B, et al. Acute exercise remodels promoter methylation in human skeletal muscle. Cell Metab 2012;15:405-11.

90. Seaborne RA, Strauss J, Cocks M, et al. Human skeletal muscle possesses an epigenetic memory of hypertrophy. Sci Rep 2018;8:1898.

91. Abel JL, Rissman EF. Running-induced epigenetic and gene expression changes in the adolescent brain. Int J Dev Neurosci 2013; 31:382-90.

92. Elsner VR, Lovatel GA, Bertoldi K, et al. Effect of different exercise protocols on histone acetyltransferases and histone deacetylases activities in rat hippocampus. Neuroscience 2011;192:580-7.

93. Naugle KM, Fillingim RB, Riley JL. A meta-analytic review of the hypoalgesic effects of exercise. J Pain 2012;13:1139-50.

94. Ieraci A, Mallei A, Musazzi L, Popoli M. Physical exercise and acute restraint stress differentially modulate hippocampal brain-derived neurotrophic factor transcripts and epigenetic mechanisms in mice. Hippocampus 2015;25:1380-92.

95. Erickson KI, Miller DL, Roecklein KA. The aging hippocampus: interactions between exercise, depression, and BDNF. Neuroscientist 2012;18:82-97.

96. Vaynman S, Ying Z, Gomez-Pinilla F. Hippocampal BDNF mediates the efficacy of exercise on synaptic plasticity and cognition. Eur J Neurosci 2004:20:2580-90.

97. Nijs J, Meeus M, Versijpt J, et al. Brain-derived neurotrophic factor as a driving force behind neuroplasticity in neuropathic and central sensitization pain: a new therapeutic target? Expert Opin Ther Targets 2015;19:565-76.

98. Nugraha B, Karst M, Engeli S, Gutenbrunner C. Brain-derived neurotrophic factor and exercise in fibromyalgia syndrome patients: a mini review. Rheumatol Int 2012;32:2593-9.

99. Nijs J, Kosek E, Van Oosterwijck J, Meeus M. Dysfunctional endogenous analgesia during exercise in patients with chronic pain: to exercise or not to exercise? Pain Physician 2012;15(Suppl 3): E205-13.

100. Pruunsild P, Kazantseval A, Aid T, Palm K, Timmusk T. Dissecting the human BDNF locus: bidirectional transcription, complex splicing, and multiple promoters. Genomics 2007;90:397-406.

101. Ehlert T, Simon P, Moser DA. Epigenetics in sports. Sports Med 2013;43:93-110.

102. Falkenberg KJ, Johnstone RW. Histone deacetylases and their inhibitors in cancer, neurological diseases and immune disorders. Nat Rev Drug Discov 2014;13:673-91.
103. Mout R, Ray M, Lee YW, Scaletti F, Rotello VM. In vivo delivery of CRISPR/Cas9 for therapeutic gene editing: progress and challenges. Bioconjug Chem 2017;28:880-4.

104. Nijs J, Nees A, Paul L, et al. Altered immune response to exercise in patients with chronic fatigue syndrome/myalgic encephalomyelitis: a systematic literature review. Exerc Immunol Rev 2014;20: 94-116.

105. Ploeger HE, Takken T, De Greef MH, Timmons BW. The effects of acute and chronic exercise on inflammatory markers in children and adults with a chronic inflammatory disease: a systematic review. Exerc Immunol Rev 2009;15:6-41.

106. Dobkin PL, Da Costa D, Abrahamowicz M, et al. Adherence during an individualized home based 12-week exercise program in women with fibromyalgia. J Rheumatol 2006;33:333-41.

107. Demmelmaier I, Dufour AB, Nordgren B, Opava CH. Trajectories of physical activity over two years in persons with rheumatoid arthritis. Arthritis Care Res 2016;68:1069-77.

108. Butow P, Sharpe L. The impact of communication on adherence in pain management. Pain 2013;154(Suppl 1):101-7.

109. Nijs J, Paul L, Wallman K. Chronic fatigue syndrome: an approach combining self-management with graded exercise to avoid exacerbations. J Rehabil Med 2008;40:241-7.

110. Bernardy K, Klose P, Busch AJ, Choy EH, Häuser W. Cognitive behavioural therapies for fibromyalgia. Cochrane Database Syst Rev 2013;9:CD009796.

111. van Ittersum MW, van Wilgen CP, van der Schans CP, Lambrecht $L$, Groothoff JW, Nijs J. Written pain neuroscience education in fibromyalgia: a multicenter randomized controlled trial. Pain Pract 2014; 14:689-700.

112. Gutierrez-Arcelus M, Ongen H, Lappalainen T, et al. Tissue-specific effects of genetic and epigenetic variation on gene regulation and splicing. PLoS Genet 2015;11:e1004958.

113. Keller S, Sarchiapone M, Zarrilli F, et al. Increased BDNF promoter methylation in the Wernicke area of suicide subjects. Arch Gen Psychiatry 2010;67:258-67.

114. Byun HM, Nordio F, Coull BA, et al. Temporal stability of epigenetic markers: sequence characteristics and predictors of short-term DNA methylation variations. PLoS One 2012;7:e39220.

115. Diamond ML, Ritter AC, Failla MD, et al. IL-1 $\beta$ associations with posttraumatic epilepsy development: a genetics and biomarker cohort study. Epilepsia 2015;56:991-1001. 